\title{
Summer sudden Na number density enhancements measured with the ALOMAR Weber Na Lidar
}

\author{
D. Heinrich ${ }^{1}$, H. Nesse ${ }^{1}$, U. Blum ${ }^{1, *}$, P. Acott ${ }^{2}$, B. Williams ${ }^{3}$, and U.-P. Hoppe ${ }^{1}$ \\ ${ }^{1}$ Norwegian Defence Research Establishment (FFI), 2027 Kjeller, Norway \\ ${ }^{2}$ Department of Physics, Colorado State University, Fort Collins CO 80523-1875, USA \\ ${ }^{3}$ NorthWest Research Associates, Colorado Research Associates division, Boulder, CO 80301, USA \\ *now at: Fraunhofer-Institute for Technological Trend Analysis, Euskirchen, Germany
}

Received: 15 December 2006 - Revised: 1 March 2007 - Accepted: 9 July 2007 - Published: 28 May 2008

\begin{abstract}
We present summer Na-densities and atmospheric temperatures measured 80 to $110 \mathrm{~km}$ above the Arctic Lidar Observatory for Middle Atmosphere Research (ALOMAR). The Weber Na Lidar is part of ALOMAR, located at $69^{\circ} \mathrm{N}$ in Norway, $150 \mathrm{~km}$ north of the Arctic Circle. The sun does not set here during the summer months, and measurements require a narrowband Faraday Anomalous Dispersion Optical Filter (FADOF).

We discuss an observed sudden enhancement in the $\mathrm{Na}$ number density around 22:00 UT on 1 to 2 June 2006. We compare this observation with previous summer measurements and find a frequent appearance of $\mathrm{Na}$ number density enhancements near local midnight. We describe the time of appearance, the altitude distribution, the duration and the strength of these enhancements and compare them to winter observations. We investigate possible formation mechanisms and, as others before, we find a strong link between these $\mathrm{Na}$ number density enhancements and sporadic E layers.
\end{abstract}

Keywords. Atmospheric composition and structure (Middle atmosphere - composition and chemistry) - Meteorology and atmospheric dynamics (Middle atmosphere dynamics; Instruments and techniques)

\section{Introduction}

The polar mesosphere is a unique region of the atmosphere. The coldest temperatures in the atmosphere, $140 \mathrm{~K}$ and colder, occur there during the summer (e.g. Lübken, 1999). Under these extremely cold conditions, Polar Mesosphere Summer Echoes (PMSE, e.g. Czechowsky et al., 1979; Balsley et al., 1983; Hoppe et al., 1988) and Noctilucent Clouds (NLC, e.g. Jesse, 1885; Fiedler et al., 2005) are observed. Both phenomena are related to ice particles in the mesopause

Correspondence to: D. Heinrich

(daniela.heinrich@ffi.no) region (e.g. Lie-Svendsen et al., 2003; Rapp and Lübken, 2004; Baumgarten and Thomas, 2006). The cold temperatures cannot be explained using the radiative heat balance alone. They are caused largely by upwelling and adiabatic expansion of air masses above the polar cap (e.g. Murgatroyd and Singleton, 1961; Garcia and Solomon, 1985; Becker and Schmitz, 2002). This upwelling is related to a modification of the mean zonal circulation due to gravity wave breaking and the resulting momentum flux divergence (e.g. Lindzen, 1981; Gavrilov et al., 2000; Fritts et al., 2002).

Regular temperature measurements with good time and altitude resolution in the polar mesosphere can only be done by lidar. Routine radiosonde measurements do not reach the mesosphere and satellite observations are only possible with a coarse altitude resolution and limited local time coverage. Meteor radars can infer the temperature from meteor trail diffusion, but their time and altitude resolution is limited. Passive rocket-borne in-situ instrumentation such as falling spheres (Lübken and von Zahn, 1991; Schmidlin, 1991) or instruments as e.g. CONE (COmbined measurements of Neutrals and Electrons, Giebler and Lübken, 1995; Rapp et al., 2001) cover a large altitude range $(35-95 \mathrm{~km}$ for falling spheres and 70-120 km for CONE), but cannot be done on a regular basis. Passive ground-based remote sensing instruments as $\mathrm{OH}$ imagers allow regular temperature measurements in the altitude of the mesospheric OH-layer (e.g. von Zahn et al., 1987; Bittner et al., 2002). However, these measurements are only possible in the restricted region of the mesospheric $\mathrm{OH}$-emission around $88 \mathrm{~km}$ altitude and in darkness.

Resonance lidars are active remote sensing instruments that measure the thermal broadening and Doppler shift of the resonance scattering spectrum of metal atoms in the upper mesosphere and lower thermosphere. Temperature measurements have been performed using $\mathrm{Na}$ (e.g. Thomas and Bhattacharyya, 1980; Fricke and von Zahn, 1985), K (von Zahn and Höffner, 1996), and Fe (Chu et al., 2002). Resonance

Published by Copernicus Publications on behalf of the European Geosciences Union. 
lidars allow precise and continuous measurements with good temporal and spatial resolution. Measurements are limited by tropospheric cloud cover and operator time.

The atomic number density has also been studied extensively with resonance lidars. The Na layer exhibits a seasonal variation with a winter maximum (Gerding et al., 2000). In polar regions the winter $\mathrm{Na}$ number density is a factor of 10 larger than during summer (Gardner et al., 1988; Kurzawa and von Zahn, 1990). Towards lower latitudes this factor is smaller and at low latitudes it is about 1.3 (Simonich et al., 1979). This seems to indicate the sensitivity of the $\mathrm{Na}$ abundance to temperature as the mesosphere is coldest during summer in polar regions (Plane et al., 2003). The altitude of the peak density varies between $88 \mathrm{~km}$ during winter and $92 \mathrm{~km}$ during summer (Gardner et al., 1988; Kurzawa and von Zahn, 1990).

An interesting phenomenon observed by studying the $\mathrm{Na}$ number density are density variations of the same order of magnitude as the seasonal variations in the polar mesosphere but on a much shorter time scale. Clemesha et al. (1978) published the first observation of a sudden $\mathrm{Na}$ density enhancement of a factor of 15 compared to the background density. The enhancement was concentrated in a thin layer of $2 \mathrm{~km}$, which apparently formed in the matter of minutes and lasted for several hours. Since then these so-called sudden sodium layers, or sporadic sodium layers, have been reported by many different groups (e.g. Gardner et al., 1988; Hansen and von Zahn, 1990; Collins et al., 1996). At polar latitudes, the phenomenon seems more frequent during the summer months. Hansen (1989) found the occurrence rate to be about a factor of 10 larger in June-August compared to November-February for 1986/87. For July/August 1987 compared to October-March 1987 this factor was found to be 1.7 (Hansen and von Zahn, 1990). In this paper we will present the summer and winter statistics that so far have been gained from observations by the ALOMAR WEBER Na lidar. Due to a very narrowband filter applied to our receiver, we are able to perform the daylight measurements necessary during summer. Over the years, we have achieved observation times more evenly distributed during the day, even during the summer months. This gives us the capability to study diurnal variations in the Na number density and the sudden number density enhancement distribution.

The large occurrence rate of Na number density enhancements during summer, together with a strong local time dependence of the phenomenon, make us question whether or not it is appropriate to call this summertime sudden density enhancement a sporadic layer, and whether sudden density enhancements in summer and winter are caused by the same formation mechanism.

Simultaneous investigations of atomic and ion layers suggest a strong link between sporadic $\mathrm{E}$ layers and sudden sodium layers (von Zahn and Hansen, 1988; Friedman et al., 2000; Collins et al., 2002). Several other mechanisms, such as e.g. meteor deposition (Clemesha et al., 1978), tem- perature dependent chemistry (Zhou et al., 1993) and auroral bombardment of smoke particles (von Zahn et al., 1987), have been suggested to produce these layers, but none of them can give an altogether satisfying explanation (Clemesha, 1994).

The Arctic Lidar Observatory for Middle Atmosphere Research (ALOMAR) on the Norwegian island Andøya $\left(69^{\circ} \mathrm{N}, 16^{\circ} \mathrm{E}\right)$ includes a wind-temperature Na-resonance lidar (She et al., 2002). The instrument has been operational since summer 2000 and has been jointly operated by Colorado State University (CSU), Colorado Research Associates (NWRA/CoRA) and the Space Physics Group at the Norwegian Defence Research Establishment (FFI). The first comprehensive measurements during polar summer were performed in June through August 2001 and then in June and July 2002 as part of the MaCWAVE/MIDAS campaign (Goldberg et al., 2004; Williams et al., 2004; Fritts et al., 2004). Since July 2002, there have been several winter measurements (e.g. Williams et al., 2006a, b). These do not require special filters to reduce background noise. In contrast, the evaluation of the summer measurements requires a careful and precise understanding of the daylight filter transmission function to be able to retrieve absolute temperatures. This is important, as both the sodium chemistry and phenomena such as PMSE and NLC are temperature dependent. In February 2006, we made technical improvements on the $\mathrm{Na}$ lidar system, allowing analysis of daylight measurements with greater accuracy.

In the following, we present daylight measurements obtained with this Na lidar in summer 2006. We give a brief introduction on the lidar system, the Faraday filter, and its influence on the measurement results. Then we present the observations on 1 and 2 June 2006 and discuss the received $\mathrm{Na}$ number density and temperature. We compare an observed sudden enhancement in Na number density with other summer measurements with the ALOMAR Weber Na Lidar and present the characteristics of sudden enhancements in $\mathrm{Na}$ number density around local midnight. We compare them to sudden sodium layers observed with our lidar during winter and investigate a possible link to sporadic E layers. All times in this paper are given in universal time (UT). ALOMAR is located at $16^{\circ} \mathrm{E}$, so local solar time is UT+64 min.

\section{The Weber Na Lidar system for daylight measure- ments}

The transmitter of the Weber Na Lidar consists of the following components. The Sum Frequency Generator laser generates the seed light at $589.159 \mathrm{~nm}$ wavelength necessary for the fluorescent excitation of $\mathrm{Na}$ atoms (Vance et al., 1998). In this Sum Frequency Generator light from two Nd:YAG lasers, one emitting near $1064 \mathrm{~nm}$ and the other near $1319 \mathrm{~nm}$, are focused into a monolithic lithium niobate $\left(\mathrm{LiNbO}_{3}\right)$ crystal. This crystal was designed as a resonator 
to give the largest possible power output. By non-linear sumfrequency generation in this resonator, about $100 \mathrm{~mW}$ of 589$\mathrm{nm} \mathrm{cw}$ narrowband radiation is produced. The frequency is locked by Doppler-free saturation spectroscopy to the saturation dip (Lamb dip) in the centre of the Doppler-broadened $\mathrm{D}_{2 a}$ line with an accuracy of $\pm 10 \mathrm{MHz}$ (She et al., 1992).

Using an acousto-optic modulator, the light is alternately shifted up and down in frequency by $630 \mathrm{MHz}$, creating a beam of three distinct frequencies in a cycle of un-shifted, up-shifted and down-shifted light. Following the acoustooptic modulator, the laser beam is amplified by a pulsed dye amplifier, which is pumped by a frequency doubled $(532 \mathrm{~nm})$ pulsed Nd:YAG laser operating at $50 \mathrm{~Hz}$ (Arnold and She, 2003). Pulses of 4.2 ns duration (FWHM) leave the pulsed dye amplifier with energy of about $15 \mathrm{~mJ}$. The positions of the three emitted frequencies relative to the $\mathrm{Na}_{2}$ transition at $589.159 \mathrm{~nm}$ are marked in Fig. 1.

The receiver collects and detects the laser light which is backscattered in the atmosphere. The backscattered photons are collected by two $1.8 \mathrm{~m}$ diameter telescopes, coupled into optical fibres, and guided to the detectors. We use photomultiplier tubes to count the photon pulses. The counted photon pulses are binned in time with respect to the laser pulse by a counting card and the data is stored in a computer. The counting card records the backscattered photons for each emitted frequency individually and allows measuring the wavelength dependence of the backscattered intensity.

For daylight observations we add one more component to the receiver, a Faraday Anomalous Dispersion Optical Filter (FADOF) (Chen et al., 1996). We insert this $3.5 \mathrm{GHz}$ FWHM broad filter between the fibre optics and the photomultiplier tubes. It consists of a Na cell, placed in a Teflon oven for temperature control and between two crossed polarisers, and a permanent axial magnetic field of $2350 \mathrm{G}$. Light entering the filter through the first polariser is blocked by the second one unless its frequency is near an atomic absorption line of $\mathrm{Na}$. Only for light of this frequency the polarisation plane will be rotated due to the Zeeman Effect and anomalous dispersion. The polarisation rotation angle is given by the strength of the magnetic field, the length of the vapour cell and the number density of the Na vapour, which is controlled by the temperature of the Na cell (e.g. She, 1997; Dick and Shay, 1991; Hedin, 2002).

The absorption Na spectrum of the $\mathrm{Na}_{2}$ resonance transition for different atmospheric conditions is shown in Fig. 1. This figure also shows the normalised transmission function for one of the two Weber lidar FADOFs. The transmission through the filter is $20 \%$ to $25 \%$. The signal is reduced by a factor of 2 by the first polariser and further losses are due to reflections at optical surfaces (She et al., 2002).

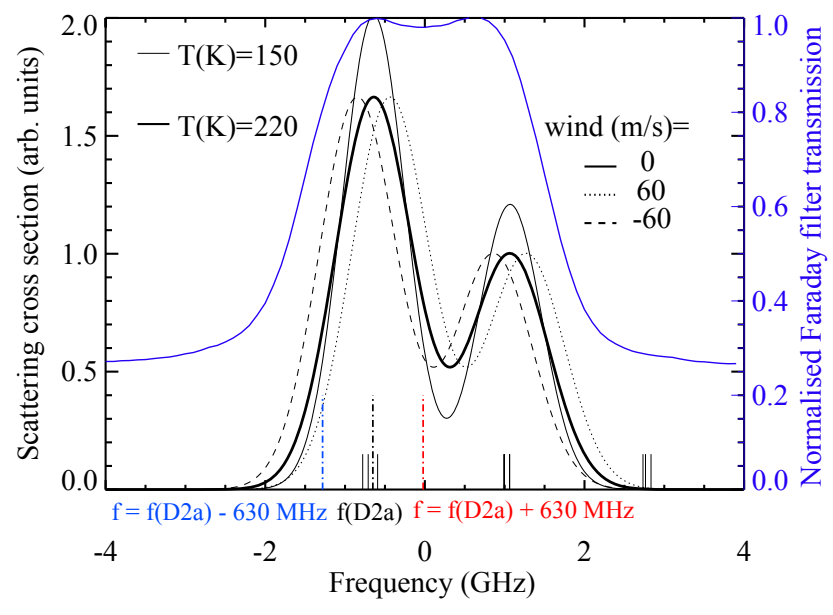

Fig. 1. The different black curves show the total backscattering cross section of the $\mathrm{D}_{2}$ resonance transition in the Na hyperfine structure for different atmospheric temperatures and winds. The transmission curve of the FADOF is plotted in blue. The three emitted frequencies are marked by the three dashed-dotted lines. The eight black vertical lines mark the received fluorescence frequencies for the $\mathrm{Na}_{2}$ transition.

\section{Data analysis}

To convert the measured backscattered photons into temperature, sodium number density and wind, we fit the theoretical shape of the spectrum of the $\mathrm{D}_{2}$ transition of the $\mathrm{Na}$ atom to the backscattered fluorescence signals at the three emitted frequencies (Fricke and von Zahn, 1985; Heinrich et al., 2005). The shape of the spectrum depends on the atmospheric temperature, the line-of-sight wind and the $\mathrm{Na}$ number density. Before the fit can be done, some raw data processing is necessary. The background must be estimated and subtracted, and we correct instrumental effects like different intensities in the three emitted frequencies or intensity changes over time. For the elimination of the instrumental effects we use the signal from Rayleigh scattering at heights well below the Na layer, but above possible stratospheric aerosol layers.

For the analysis of daylight measurements we must know the exact FADOF transmission at the different wavelengths received. This very narrowband filter modifies both the $\mathrm{Na}$ signal and the Rayleigh signal. We will briefly describe this special aspect of daylight analysis in the following two sections.

\subsection{The Rayleigh signal}

We receive a signal from Rayleigh and aerosol scattering from the troposphere and up to the upper stratosphere. We use the Rayleigh signal from altitudes around $30 \mathrm{~km}$ to normalise the intensity at the three emitted frequencies. At these altitudes, we can safely assume that the backscattered signal 

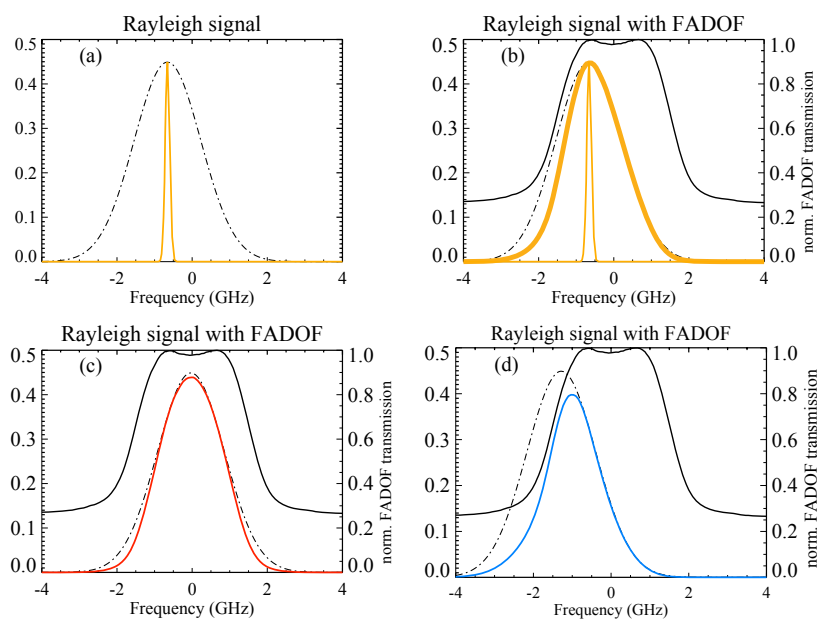

Fig. 2. The backscattered Rayleigh signal is doubly Doppler broadened. Figure 6a shows the line shape of the laser beam and the backscattered Rayleigh signal for $250 \mathrm{~K}$ atmospheric temperature (dashed-dotted line). The FADOF reduces this signal as shown in (b) for the un-shifted beam (thick yellow line). In Figs. 6b-d also the normalised FADOF transmission is plotted (solid black line). The reduced backscattered Rayleigh signal of the up-shifted beam (red) and of the down-shifted beam (blue) are shown in (c) and (d), respectively.

is pure Rayleigh scattering. We use the integrated Rayleigh signal over an altitude range of $5 \mathrm{~km}$ in which all three frequencies have a good Rayleigh signal. The integrated signal provides the reference intensity for each frequency.

For daylight measurements, we add the FADOF. In this case we must first correct the received Rayleigh signal for the transmission through the FADOF. The Rayleigh scattering is affected by the Doppler broadening caused by the thermal motion of the scatterers in the atmosphere. The backscattered light undergoes Doppler broadening twice, once during absorption and again during reemission. The line shape of the emitted spectrum and the received spectrum from Rayleigh scattering for the un-shifted frequency are shown in Fig. 2a. We assume $250 \mathrm{~K}$ as the temperature at $30 \mathrm{~km}$ in this calculation (Lübken, 1999). We assume the line-of-sight wind as $0 \mathrm{~m} / \mathrm{s}$. This corresponds to the expected average wind for measurements with a beam pointed at zenith, the preferred setting for our summer measurements. Figure $2 b$ shows the influence of the FADOF on this signal and panels (c) and (d) display the influence of the filter on the Rayleigh signal from the up-shifted and down-shifted beams, respectively. These three signal changed differently by the FADOF. Neglecting the influence of the FADOF would result in a wrong normalisation of the three emitted frequencies against each other and by this in a systematic error in the Na temperatures.

For a more precise analysis, we use the temperature and the wind at the Rayleigh altitude from the ECMWF (European Centre for Medium-Range Weather Forecasts) T106 model data. We have estimated the influence of the temperature and the line-of-sight wind at Rayleigh altitudes by analysing $\mathrm{Na}$ temperatures with these parameters artificially modified. We found that an assumed error in the temperature at Rayleigh altitudes of $50 \mathrm{~K}$ leads to an error of $2.5 \mathrm{~K}$ in the derived $\mathrm{Na}$ temperature. Overestimating the temperature at Rayleigh altitudes results in overestimating the $\mathrm{Na}$ temperatures. Winds in the atmosphere can cause a Doppler shift in the Rayleigh scattering signal. An overestimate of the line-of-sight wind at Rayleigh altitudes by $100 \mathrm{~m} / \mathrm{s}$ results in a derived temperature too large by $2 \mathrm{~K}$ at sodium altitudes. Compared to other uncertainties, the likely error in the ECMWF data result in a negligible error in the Na temperatures. After correcting the Rayleigh signals for their FADOF transmission, we can use them to normalise the intensities of the two shifted frequencies to the intensity of the unshifted beam.

\subsection{The Na signal}

We must take into account the transmission of the FADOF also when we fit the backscattered $\mathrm{Na}$ signal to the spectrum of the $\mathrm{D}_{2}$ transition. The Na signal is Doppler broadened and Doppler shifted by the wind. The absorption spectrum for the $\mathrm{D}_{2}$ resonance transition of the Na hyperfine structure for two typical temperatures and three typical winds is plotted together with the FADOF transmission in Fig. 1. We emphasize the importance of the knowledge of exact filter transmission. We must include it in the fit procedure in a way that adjusts the measured signal correctly for all possible temperatures and winds.

The light from the lidar is absorbed by a given $\mathrm{Na}$ atom only when the frequency is equal to one of the six hyperfine transitions in the $\mathrm{D}_{2}$ resonance line in its own coordinate system. As the $\mathrm{Na}$ atoms move, the requirement for absorption is given by Eq. (1). Motion away from the observer in the line-of-sight direction has a positive sign and towards the observer a negative sign.

$v_{\text {hyperf.trans. }}=v_{\text {laser }}+v_{\text {Doppler }}$

The atom reemits with a time constant of about $10^{-8} \mathrm{~s}$ a photon at one of the frequencies of the hyperfine transitions in its rest frame. The absorbed photon has insufficient momentum to substantially change the motion of the atom. The time between $\mathrm{Na}$ atom collisions is about $10^{-4} \mathrm{~s}$ and thus does not play a role in this context.

The frequency emitted from the $\mathrm{Na}$ atom, seen of an observer on the ground, is

$$
\begin{aligned}
v_{\text {emitted atom }} & =v_{\text {hyperf.trans. }}+v_{\text {Doppler }} \\
& =v_{\text {hyperf.trans. }}+\left(v_{\text {hyperf.trans. }}-v_{\text {laser }}\right) \\
& =2 \cdot v_{\text {hyperf.trans. }}-v_{\text {laser }} .
\end{aligned}
$$

Equation (2) shows that the backscattered frequency is independent of the Doppler shift. Resonance fluorescence is a 

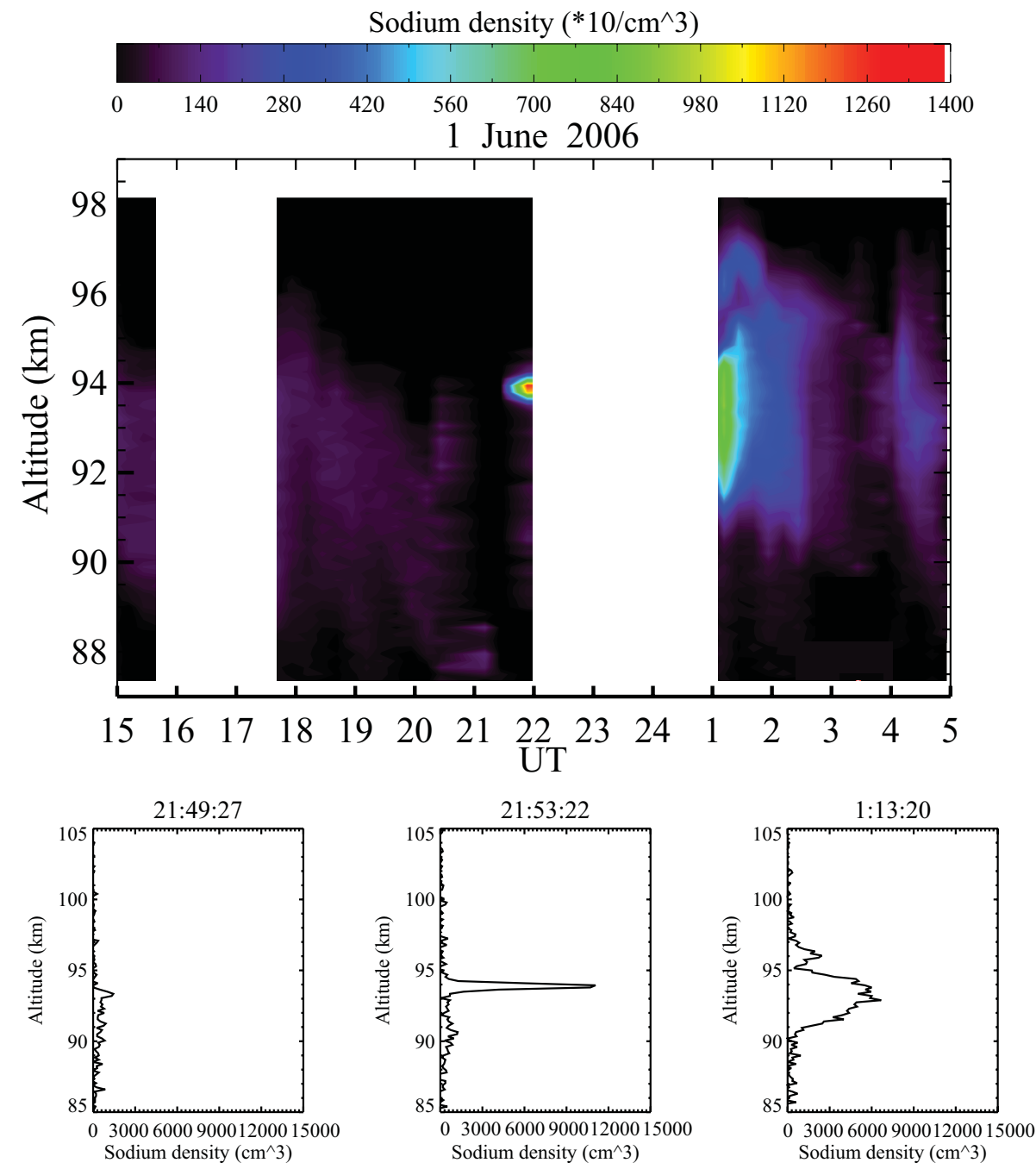

Fig. 3. The Na number density measured on 1-2 June 2006 with the Weber Na Lidar at ALOMAR and profiles of the Na layer at three different times.

combination of excitation and emission processes. For the $\mathrm{Na}_{2}$ transition, ten fluorescence pathways are allowed due to quantum mechanical selection rules (Chen et al., 1996). These ten fluorescence pathways result in eight different frequencies emitted by the excited atom. These eight frequencies are marked in Fig. 1 by the short black lines above the $\mathrm{x}$-axis. For the daylight data analysis the correct FADOF transmission for these backscattered frequencies has to be included in the mathematical description of the fluorescence spectrum.

\section{Summer observations}

We have made summer measurements with the ALOMAR Weber Na Lidar since 2000. In summer 2006, the Space Physics Group at FFI performed a measurement campaign at ALOMAR from mid-May until mid-August. Because of cloudy weather, the result of this ten-weeks-long summer campaign was only two nights of data. During summer, two aspects make measurements much more difficult than in winter. First, the sky background radiation is very strong, as the sun does not set. Second, in polar regions the Na number density is as much as 10 times smaller in summer compared to winter (e.g. Plane, 2003).

\subsection{Sudden enhancements in Na number density}

Figure 3 shows the Na number density measured during the night from 1 to 2 June 2006 and the profiles of the Na layer at 21:49, 21:53 and 01:13 UT. We estimated the Na density with a spatial resolution of $150 \mathrm{~m}$ and a temporal resolution of $15 \mathrm{~min}$. From about 15:30-17:30 UT and 22:3001:00 UT, no measurements were possible due to clouds. Around 22:00 UT we observed a strong increase in the Na signal at about $94 \mathrm{~km}$ altitude, about ten times larger $\mathrm{Na}$ 


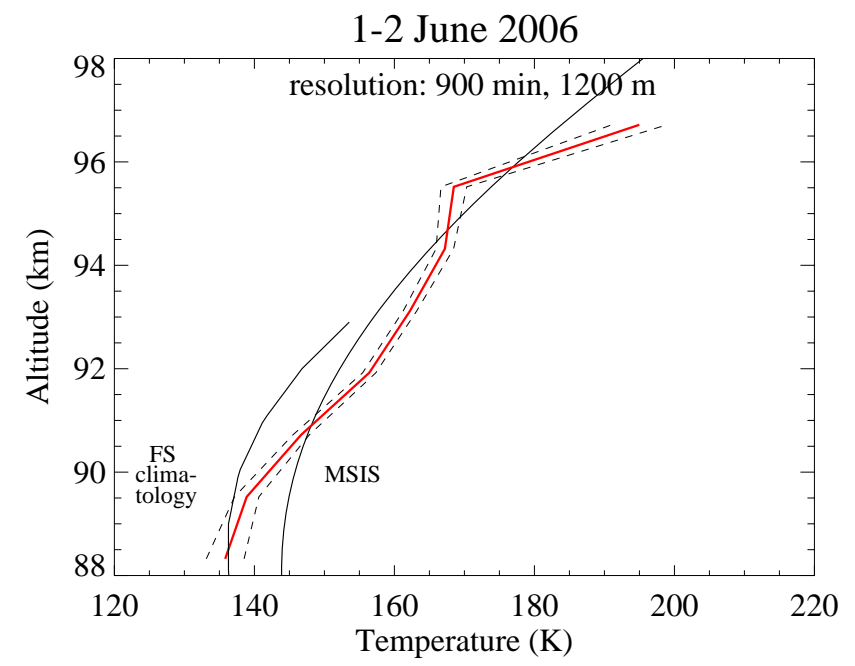

Fig. 4. The mean temperature profile for the whole measuring time is plotted as the solid red line. The dashed lines show the statistical error of the temperature. Two reference temperature profiles are also plotted, the monthly mean temperature for June (Lübken, 1999) and the daily temperature profile from the MSISe90 model (Hedin, 1991).
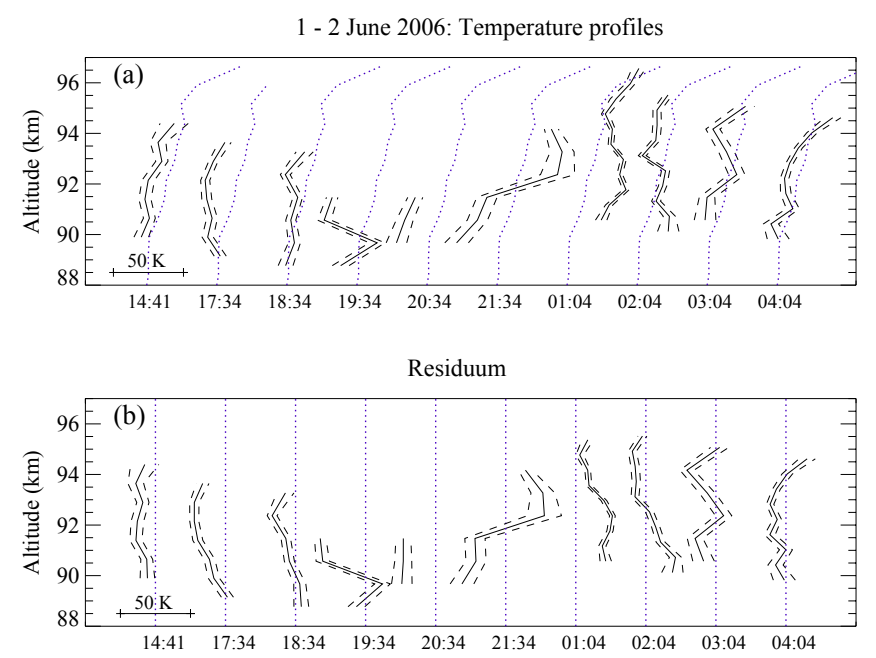

Fig. 5. Hourly mean temperature profiles (a) and their differences from the mean temperature (b) are plotted in this figure. The corresponding time is given underneath each profile. The temperature profiles are moved by $50 \mathrm{~K}$ from one profile to the next one. The dotted lines in (a) represent the mean temperature profile, the ones in (b) the $0 \mathrm{~K}$.

number density compared to the density of the 6 preceding hours (Fig. 3). This increased Na density presumably spread in altitude over time and spanned an altitude range from 91 to $97 \mathrm{~km}$ at 01:30 UT. Afterwards, it slowly decreased during the morning hours. The lack of data in the time from 22:00 UT to 01:00 UT prevents us from learning more about the formation of this much increased intensity.

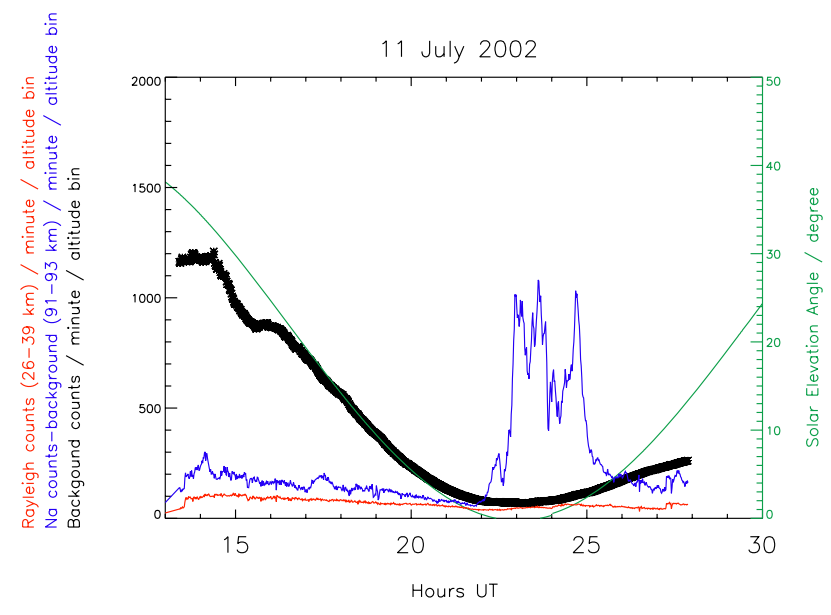

Fig. 6. The integrated $\mathrm{Na}$ counts from an altitude interval from 91 to $93 \mathrm{~km}$, is plotted in blue against the measuring time. The background is plotted in black and the solar elevation angle in green. The Rayleigh signal is given in red.

The mean temperature profile for the measurement period is shown in Fig. 4. At the same time, two reference temperature profiles are plotted for falling sphere (FS) observations (Lübken, 1999) and the MSISe90 model (Hedin, 1991).

Hourly mean temperature profiles and their differences from the observed mean temperature are plotted in Fig. 5. The corresponding starting time for each profile is given underneath it. The temperature profiles are shifted by $50 \mathrm{~K}$ from one profile to the next one. The profiles show a temperature increase around the same time (21:50 UT) and at about the same altitude as the enhancement in the $\mathrm{Na}$ signal. The temperature increase may have caused the increase in sodium number density. As described in Sect. 1, the seasonal sodium density variations suggest a sensitivity of $\mathrm{Na}$ chemistry to temperature (Zhou et al., 1993; Plane, 2003). Zhou et al. (1993) suggest that an increase in the mesopause temperature by $10 \mathrm{~K}$ may double the sodium concentration. We discuss this further in Sect. 4.4 below.

During summer, the $\mathrm{Na}$ density has a relatively stronger variability compared to winter. However, we found that for all our summer night measurements the $\mathrm{Na}$ density increased within two hours around local midnight. We have observations around local midnight on eleven days over four years. All enhancements that we observed occurred near the time of lowest solar elevation. This is shown in Fig. 6 for measurements done on 11 July 2002. We have plotted the Rayleigh signal (red), the background (black), the solar elevation angle (green) and the background subtracted $\mathrm{Na}$ signal (blue) integrated from 91 to $93 \mathrm{~km}$. The signal suddenly increased and stayed about 8 times larger than the average signal of the previous $8 \mathrm{~h}$ while the sun was at its lowest elevation. This led us to investigate a possible influence of the solar radiation on the apparent $\mathrm{Na}$ number density. We calculated the 
Table 1a. Observations of sudden Na enhancements above ALOMAR during June and July.

\begin{tabular}{lcccc}
\hline Date & \multicolumn{2}{c}{ Time (UT) } & $\begin{array}{c}\text { Altitude at onset } \\
(\mathrm{km})\end{array}$ & $\begin{array}{c}\text { Factor of } \\
\text { enhancement }\end{array}$ \\
\hline 1 June 2006 & $21: 48$ & $02: 00$ & 93.9 & 10 \\
18 July 2005 & $21: 41$ & $23: 10$ & 93 & 10 \\
20 July 2005* & $21: 04-22: 11$ & $02: 55$ & 92 & 2 \\
25 June 2002 & $15: 58$ & $17: 08$ & 95 & 6 \\
25 June 2002 & $22: 45$ & $02: 20$ & 92.6 & $2-3$ \\
1 July 2002 & $21: 00$ & $21: 15$ & 94.5 & 5 \\
1 July 2002 & $21: 07$ & $08: 00$ & 92.5 & 6 \\
2 July 2002* & $21: 50-23: 09$ & $00: 05$ & 93 & 8 \\
4 July 2002 & $01: 00$ & $06: 45$ & 94,5 & 5 \\
11 July 2002 & $21: 17$ & $21: 37$ & 95 & 5 \\
11 July 2002 & $22: 45$ & $01: 50$ & 92 & $10-15$ \\
19 June 2001 & $23: 50$ & after 02:05 & 93.2 & 10 \\
20 June 2001 & $23: 25$ & $23: 31$ & 94.5 & 4 \\
20 June 2001 & $23: 33$ & $01: 10$ & 93.6 & 6 \\
6 July 2001 & $00: 17$ & $02: 25$ & 94 & 10 \\
6 July 2001 & $00: 25$ & $00: 55$ & 97 & \\
\hline
\end{tabular}

* onset not observed

possible saturation of $\mathrm{Na}$ atoms by solar photons. Because of stimulated emission, the maximum saturation would mean that exactly half of the $\mathrm{Na}$ atoms are in an excited state, making them invisible to our lidar. We define the saturation level as the radiation field generating half of this maximum value. Using the ratio of the Einstein's coefficients for these transitions and their natural linewidth, we estimate the saturation intensity for unpolarised light as about $12 \mathrm{~mW} / \mathrm{cm}^{2}$. The intensity of the radiation from the sun at $589 \mathrm{~nm}$, however, is a factor of 1000 smaller. Therefore, this cannot explain the observed enhancement.

Sudden enhancements of $\mathrm{Na}$ number density observed from Andøya $\left(69^{\circ} \mathrm{N}, 16^{\circ} \mathrm{E}\right)$ were first described by von Zahn et al. (1987). They defined a sudden enhancement of the $\mathrm{Na}$ density (typical time constant: $5 \mathrm{~min}$ ) in a narrow altitude range (about $1 \mathrm{~km}$ ) as a Sudden Sodium Layer (SSL). By definition, the normal profile of $\mathrm{Na}$ density is not noticeably affected by the development of the SSL. These layers emerge at altitudes between 90 and $110 \mathrm{~km}$ and have 2 to 20 times larger densities than the background layer. The Na number density enhancement that we observed around 21:50 UT fulfils all these requirements (Fig. 3). However, the enhancement in density observed after 01:00 UT spanned a large altitude range and affected the whole layer.

Looking at all our observations, we find that the Na number density enhancement in nine of our eleven summer midnight measurements happened suddenly (5 to $10 \mathrm{~min}$ ), started between 92 and $94.5 \mathrm{~km}$ altitude, and stayed for several hours (Table 1a). Table 1a lists the dates for the observations of sodium enhancements together with their onsets and endings, altitudes at onset, and the factors of enhancement. For the other two nights, we cannot say anything about the characteristics of the enhancement due to a lack of data in the hour before we observed it. However, they are found in the same altitude range and lasted for at least one hour. The altitude range corresponds to the altitudes where the largest $\mathrm{Na}$ densities in the average summer density profile are found (Hansen and von Zahn, 1990). Only one of the Na number density enhancements (Table 1a) happened at the topside of the summer Na layer. This enhancement at $97 \mathrm{~km}$ altitude was one peak of the double-layered sudden $\mathrm{Na}$ density enhancement on 6 July 2001. This will be discussed in Sect. 4.2.

We see large differences in the observed development of the Na number density enhancements. For three of the nine cases, when we were able to measure during the beginning of the event, we found a strong, short-lifetime enhancement ten minutes before the observed long-duration sudden enhancement at $1-3 \mathrm{~km}$ higher altitudes. The densities of these enhancements were not so striking compared to the density in the centre of the Na layer. In any case, the enhancement relative to the background density was substantial. This feature can be seen in the measurement from 1 July 2002 at $94.5 \mathrm{~km}$ altitude about $10 \mathrm{~min}$ before the main enhancement started (Fig. 7). A weak sodium layer prior to the main sporadic layer was also seen on 5 July 2002, as reported by Williams et al. (2006c).

In $65 \%$ of our measurements, the main sudden enhancement happened between 21:10 and 22:45 UT. A special characteristic of the enhancement of Na number density during summer was that in $55 \%$ of the cases, it was not a typical sudden sodium layer as defined by von Zahn and Hansen (1988). In $22 \%$ of the cases, it starts out about 3 to $6 \mathrm{~km}$ 


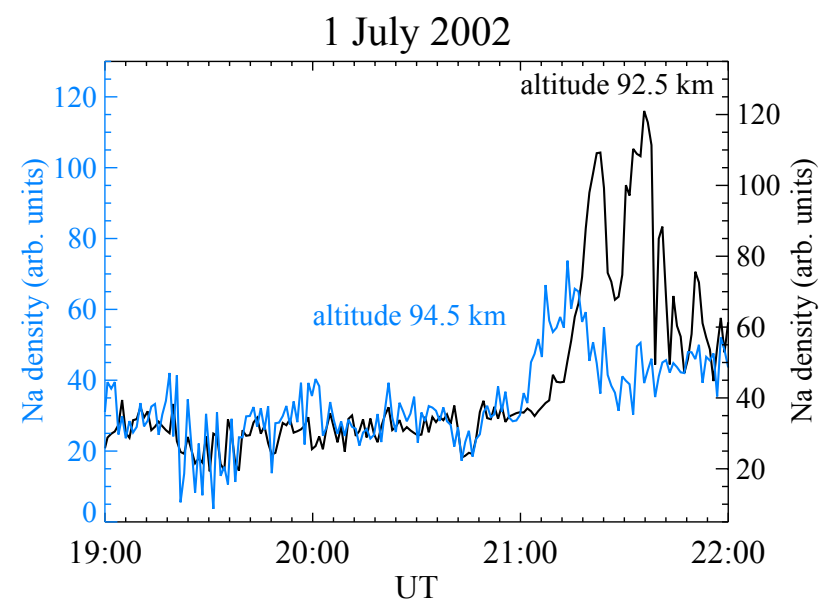

Fig. 7. The plot shows the sudden $\mathrm{Na}$ density enhancement at 1 July 2002. We observed a strong, short-lifetime enhancement ten minutes before the observed long-duration sudden enhancement at a $2 \mathrm{~km}$ higher altitude.

wide. In the other $33 \%$ the layer started out like a typical SSL but grew broader to about 3 to $4 \mathrm{~km}$ in less then half an hour and stayed that broad. We found this behaviour for example in the night of 1-2 June 2006 presented earlier (Fig. 3). The sudden enhancements in Na density above ALOMAR around midnight during summer seem to differ from those observed during winter (see below) and those observed during summer at other sites (Williams et al., 2007). For this reason and because of their regular appearance, we avoid the term sudden sodium layer or sporadic sodium layer in this context similar to Friedman et al. (2000).

The described enhancement can also be seen in the average diurnal variation of the $\mathrm{Na}$ density for June-August above ALOMAR (Fig. 8). This figure summarises 253 measurement hours from 34 different days over the years 2001, 2002, 2005 and 2006. The distribution of total lidar observation time per hour over the day from June to August is also shown in Fig. 8. The Na density shows a significant diurnal variation. It increases starting at about 20:00 UT with a first maximum around UT midnight. The strongest maximum is found near 04:00 UT. After 04:00 UT the layers decay quickly. The variation between about 20:00 UT and 04:00 UT seems to reflect the long duration and the slow decay of the regular sudden Na number density enhancements starting from 21:00 UT. Kurzawa and von Zahn (1989) found a similar diurnal $\mathrm{Na}$ density variation for the measurements during summer 1987 and 1988 at Andøya.

\subsection{Comparison to winter observations of sporadic sodium layers}

Table $1 \mathrm{~b}$ displays an overview of the sporadic Na layers observed in the months October-March from 2000-2006. In this time period we have observed 15 layers during 11 nights
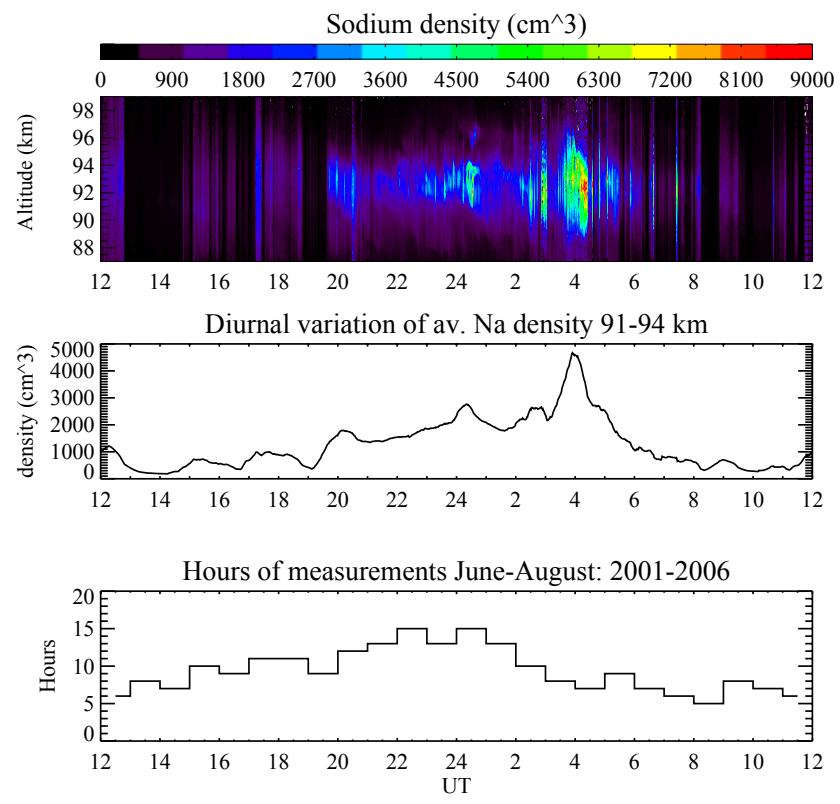

Fig. 8. The two upper panels show the average diurnal variation of the Na number density above ALOMAR for June-August. The bottom panel displays the distribution of total observation time for our lidar in each hour over the day from June to August for the years 2001-2006.

out of 24 nights with measurements around midnight. Even taking into account the greater number of measurements during winter, we find that the sudden $\mathrm{Na}$ density enhancements are almost twice as frequent in June and July compared to the months October-March. This factor gets larger and is about 2.5 if we only focus on November-February. In Fig. 10, we have plotted the number of observed sodium number density enhancements per hour of lidar observation time against the time of day of their development for summer and winter. Hansen and von Zahn (1990) observed a similar distribution. Compared to them, we find a larger difference in the number of observed enhancements per hour for summer and winter measurements. With one exception, we observed enhancements during summer only after 21:00 UT, while Hansen and von Zahn (1990) report 20:00 LT (19:00 UT). With an abrupt rise at 21:00 UT we obtained the largest number of sodium number density enhancements between 21:00 UT and 22:00 UT during summer.

The density enhancements of the sudden layers are more pronounced in June and July than the ones appearing in the winter months. During winter, the relative density enhancement is approximately a factor of 3.5 , while during summer we find that the density enhancements, is on average a factor of about 6 . Another distinct difference between the summer and winter sudden density enhancements is their duration. During summer, the enhancement usually lasts at least $1 \mathrm{~h}$ before it disappears, while during winter the duration is significantly shorter. In winter, only 1 of the 15 observed layers 
Table 1b. Observations of sudden Na layers above ALOMAR from November until March.

\begin{tabular}{|c|c|c|c|c|}
\hline \multirow[t]{2}{*}{ Date } & \multicolumn{2}{|c|}{ Time (UT) } & \multirow{2}{*}{$\begin{array}{l}\text { Altitude at onset } \\
\qquad(\mathrm{km})\end{array}$} & \multirow{2}{*}{$\begin{array}{c}\text { Factor of } \\
\text { enhancement }\end{array}$} \\
\hline & onset & end & & \\
\hline 18 February 2006 & $00: 27$ & $01: 40$ & 101 & $2-3$ \\
\hline 4 February 2006 & $21: 34$ & $22: 00$ & 102 & 3 \\
\hline 19 November $2005^{*}$ & $21: 07-22: 02$ & $22: 26$ & 101 & 4 \\
\hline 5 November 2005 & $22: 31$ & $22: 40$ & 105 & 3 \\
\hline 5 November 2005 & $23: 14$ & $22: 44$ & 92 & $3-4$ \\
\hline 7 February 2005 & $19: 39$ & $20: 01$ & 103 & 4 \\
\hline 7 February 2005 & $19: 47$ & $21: 20$ & 110 & 4 \\
\hline 28 January 2003 & $20: 26$ & $20: 41$ & 104 & 3 \\
\hline 14 January 2002 & $22: 10$ & after 22:27 & 98 & 3 \\
\hline 27 March 2001 & $20: 41$ & 20:59 & 105 & 4 \\
\hline 23 March 2001 & $20: 15$ & $20: 24$ & 103 & 5 \\
\hline 23 March 2001 & $21: 25$ & after $22: 11$ & 108 & $2-3$ \\
\hline 22 March 2001 & $20: 16$ & $20: 30$ & 104 & 5 \\
\hline 17 March 2001 & $20: 23$ & $21: 13$ & 103 & 4 \\
\hline 17 March 2001 & $22: 28$ & $22: 56$ & 101 & $2-3$ \\
\hline
\end{tabular}

* onset not observed

lasted for more than $1 \mathrm{~h}$. The three cases during summer with shorter durations, which are also listed in Table 1a, were all associated with an enhancement with a long duration. In $33 \%$ of the summer observations, the layered density enhancement seemed to diffuse in altitude, finally producing an enhanced density that rather looked like an enhanced background density than a sporadic layer. This is a feature not found in the winter observations.

The height distribution of the sudden density enhancement in winter was wider and located at higher altitudes compared to summer. The 15 winter layers were located between 92 and $110 \mathrm{~km}$, while in summer the density enhancement with just one exception, took place between 92 and $95 \mathrm{~km}$. This altitude difference is in accordance with the broader normal density layer in winter compared to summer.

The previously mentioned exception to the typical altitude distribution is the enhancement in $\mathrm{Na}$ number density observed at 00:25 UT on 6 July 2001. In this case, the density enhancement is comparable to that observed during winter. It happened at $97 \mathrm{~km}$ altitude on the topside of the sodium layer, it did not disappear into an increased background layer, and we observed the strongest enhancement only for about 20 min (Fig. 9).

In spite of the many differences we have mentioned, the local time distribution does not seem to vary significantly between summer and winter (Fig. 10). Only the sudden $\mathrm{Na}$ number density enhancement on 25 June 2002 at 15:58 UT did not occur in the time window between 21:00 UT and 06:00 UT. This is to our knowledge the first reported sudden Na density enhancement observed before 18:00 UT at Andøya.

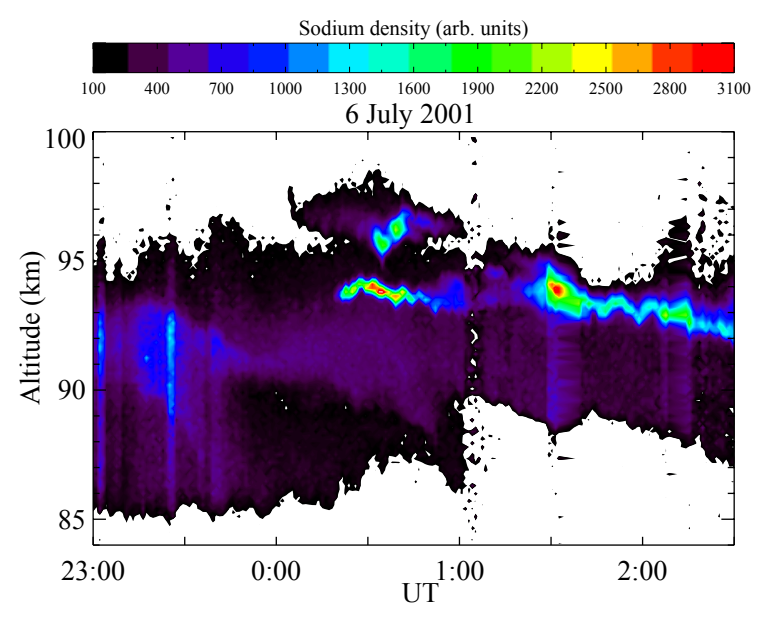

Fig. 9. The Na number density enhancement observed on 6 July 2001. The enhancement at $97 \mathrm{~km}$ altitude at the topside of the sodium layer is similar to SSLs we observe above ALOMAR during winter. It did not disappear into an increased background layer and the strongest enhancement was only present for about $20 \mathrm{~min}$.

\subsection{Link to sporadic E layers?}

Different formation mechanisms for sudden sodium layers have been proposed, but none of them seem to provide an altogether adequate explanation for all the observations. However, a strong link between sudden sodium layers and sporadic E layers has been established (von Zahn and Hansen, 1988; Hansen and von Zahn, 1990). When linked to a sporadic $\mathrm{E}$ layer, the amount of $\mathrm{Na}$ necessary for the $\mathrm{SSL}$ is believed to result from the conversion of $\mathrm{Na}^{+}$in the associated 
Table 2. Observations of sporadic E-layers at times before and after the arising of a sporadic Na-layer.

\begin{tabular}{|c|c|c|c|c|c|c|c|c|c|}
\hline $\begin{array}{l}\text { Day } \\
\text { (Onset SSL) }\end{array}$ Minutes & -40 & -30 & -20 & -10 & $\begin{array}{c}\text { Onset } \\
\text { SSL }\end{array}$ & +10 & +20 & +30 & +40 \\
\hline 19June 01 (23:50 UT) & - & - & - & - & - & $\sqrt{ }$ & $\sqrt{ }$ & $\checkmark$ & - \\
\hline 20 June 01 (23:30 UT) & - & - & - & - & - & ? & $\sqrt{ }$ & $\checkmark$ & $\checkmark$ \\
\hline 06 July 01 (00:00 UT) & - & $\sqrt{ }$ & $\checkmark$ & $\sqrt{ }$ & $\sqrt{ }$ & $\checkmark$ & $\sqrt{ }$ & $\checkmark$ & $\sqrt{ }$ \\
\hline 25 June 02 (22:45 UT) & $\checkmark$ & $\checkmark$ & $\checkmark$ & $\checkmark$ & $\checkmark$ & $\checkmark$ & $?$ & $\checkmark$ & $\sqrt{ }$ \\
\hline 1 July 02 (21:10 UT) & - & - & - & $\sqrt{ }$ & $\checkmark$ & $\checkmark$ & $\sqrt{ }$ & $\checkmark$ & $\sqrt{ }$ \\
\hline 4 July $02 \quad$ (01:00 UT) & - & $?$ & $\checkmark$ & $?$ & $\checkmark$ & - & - & - & - \\
\hline 11 July 02 (21:40 UT) & ? & & $?$ & $\checkmark$ & $\checkmark$ & $\checkmark$ & $\checkmark$ & $\checkmark$ & - \\
\hline 18 July 05 (21:40 UT) & - & - & $\sqrt{ }$ & $\sqrt{ }$ & $\sqrt{ }$ & $\checkmark$ & $\sqrt{ }$ & $\sqrt{ }$ & $\checkmark$ \\
\hline 1 June 06 (21:48 UT) & - & - & - & - & $\sqrt{ }$ & $\checkmark$ & $\checkmark$ & $\checkmark$ & $\checkmark$ \\
\hline
\end{tabular}

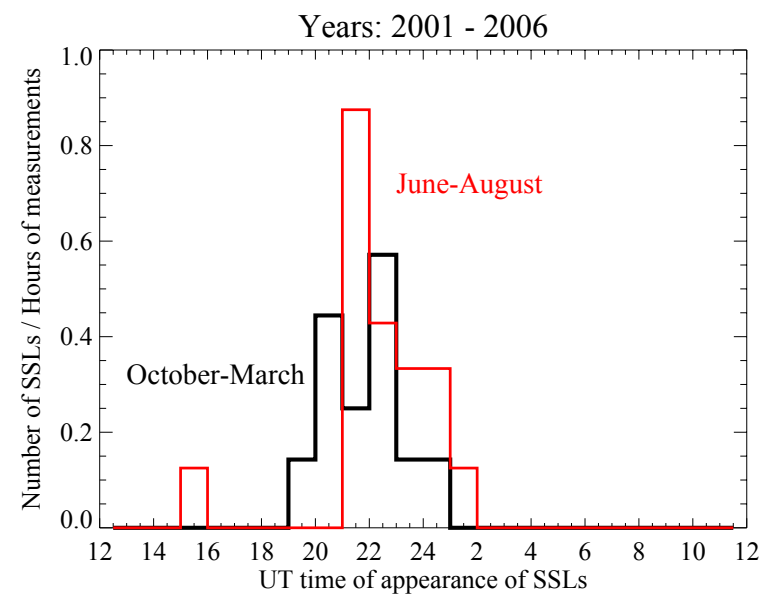

Fig. 10. The number of observed Na number density enhancements per hour of lidar observation time plotted as a function of the time of day of their appearance for summer (red) and winter (black).

$\mathrm{E}_{s}$ layers to $\mathrm{Na}$ through clustering reactions involving $\mathrm{N}_{2}$, $\mathrm{CO}_{2}$ and $\mathrm{H}_{2} \mathrm{O}$ (Collins et al., 2002).

Given their differences in altitude, strength, and duration, it is possible that the winter and summer sodium layers may not have the same production mechanism.

Comparing the diurnal variation of sporadic $\mathrm{E}$ layers with the density variation of the Na layer indicates a possible connection between them. Sporadic E layers at high latitudes in an altitude range between $90 \mathrm{~km}$ and $100 \mathrm{~km}$ occur most often during June, July and August and between 20:00 UT and 06:00 UT (Kirkwood, 1997).

To investigate the presence of sporadic $\mathrm{E}$ layers we used ionograms from the EISCAT Troms $\emptyset$ Dynasonde. This digi- tal HF sounder is located at Ramfjorden $\left(69^{\circ} \mathrm{N}, 19^{\circ} \mathrm{E}\right)$ about $120 \mathrm{~km}$ east from Andøya. We have studied the ionograms for each case in a time window of 40 min before and after the observed sudden $\mathrm{Na}$ density enhancement. The results are presented in Table 2. The presence of a sporadic E layer at a given time is marked by a check mark; otherwise a minus is set for that time. A question mark indicates that we could not identify either a sporadic E layer or the total absence of such a layer. Empty spaces mean that no ionograms exists for the corresponding times. In all cases, a sporadic E layer was observed in a time window of $20 \mathrm{~min}$ before and after the appearance of the SSL. In six of the nine cases, the sporadic $\mathrm{E}$ layer was present (120 km east of ALOMAR) before the SSL onset.

The sporadic E layer observed at Troms $\varnothing$ on 1 June 2006 at 22:00 UT had a critical frequency of $4 \mathrm{MHz}$. At 22:12 UT the critical frequency was $12 \mathrm{MHz}$. Calculating the electron densities for these times we find them to be $3.17 \times 10^{6} \mathrm{~cm}^{-3}$ and $2.6 \times 10^{8} \mathrm{~cm}^{-3}$, respectively. If the atomic $\mathrm{Na}$ was produced from $\mathrm{Na}$ ions, the concentration of $\mathrm{Na}$ ions had to be at least $3.5 \%$ of the electron density at 22:00 UT and $0.04 \%$ at 22:12 UT. For altitudes above $100 \mathrm{~km}$, the $\mathrm{Na}^{+}$concentration can vary between $5 \%$ and $35 \%$ of the electron density (Collins, 2002). We found that for the observed $\mathrm{Na}$ number density enhancement at about $94 \mathrm{~km}$, the sporadic E layers had a large enough $\mathrm{Na}$ ion concentration to produce the observed $\mathrm{Na}$ density enhancement at both times. A more detailed discussion of the connection between sporadic E-layers and sporadic Na-layers is published by Nesse et al. (2008) and Williams et al. (2006c). 
4.4 Other mechanisms to explain sudden $\mathrm{Na}$ density enhancements

A number of other explanations for sporadic sodium layers have been published. These include direct input through meteor ablation (Clemesha et al., 1978), energetic auroral particles that sputter $\mathrm{Na}$ off the surface of meteoric smoke particles (von Zahn et al., 1987) and temperature dependent chemistry (Hoppe, 1985; Zhou et al., 1993). A large temperature gradient can be caused by gravity waves. An example of extreme temperature and wind gradients near the summer mesopause caused by gravity wave dissipation and the resulting momentum flux divergence has been published by Fritts et al. (2004). The large positive temperature gradient that they found in summer allowed ice particles to form below $90 \mathrm{~km}$ and at the same time large $\mathrm{Na}$ densities above $90 \mathrm{~km}$. Na is absorbed by these ice particles, leaving no free $\mathrm{Na}$ atoms in the presence of PMSE or NLC. In our measurements from 1 to 2 June 2006 the enhancement in Na density was subsequent to an increase in temperature of about $30 \mathrm{~K}$ at altitudes above $90 \mathrm{~km}$. Figure 11 displays this temperature increase starting at about 21:30 UT and thus about $20 \mathrm{~min}$ before the Na number density enhancement at 21:49 UT. This temperature perturbation may have been wave-induced, with an ensuing Na-density enhancement (Gardner, 1995). In the density-plot (Fig. 3) it can be seen that the Na layer itself is deformed. The decay of the sudden $\mathrm{Na}$ enhancement in altitude with time appears to be related to the wave activity that night, but we have no suggestion of how this might be explained.

\section{Conclusions}

We have determined $\mathrm{Na}$ densities and temperatures from daylight lidar measurements. We have found that the $\mathrm{Na}$ layer is very dynamic during summer. This can be seen in both the Na number density and the temperature. We have presented these characteristics of the sodium layer for 1-2 June 2006. Around 21:50 UT (22:50 LT) a sudden Na number density enhancement appeared. We have compared this observation to previous measurements with the ALOMAR Weber $\mathrm{Na}$ lidar. Almost all of the sudden Na enhancements that we have observed occurred within two hours around local midnight, although with different strength. They all arose around the same altitude and 65\% occurred between 21:10 UT and 22:45 UT. More than half of them are not what would be defined as typical sudden sodium layers as they started out 4 to $5 \mathrm{~km}$ wide or became much wider with time. The altitude, strength and duration of the summer Na density enhancements is different from the winter sudden sodium layers. However, the diurnal variation of the Na number density is similar during summer and winter. Thus, it is not clear whether the summer and the winter layers have the same source. We discussed the density enhancements in connec-

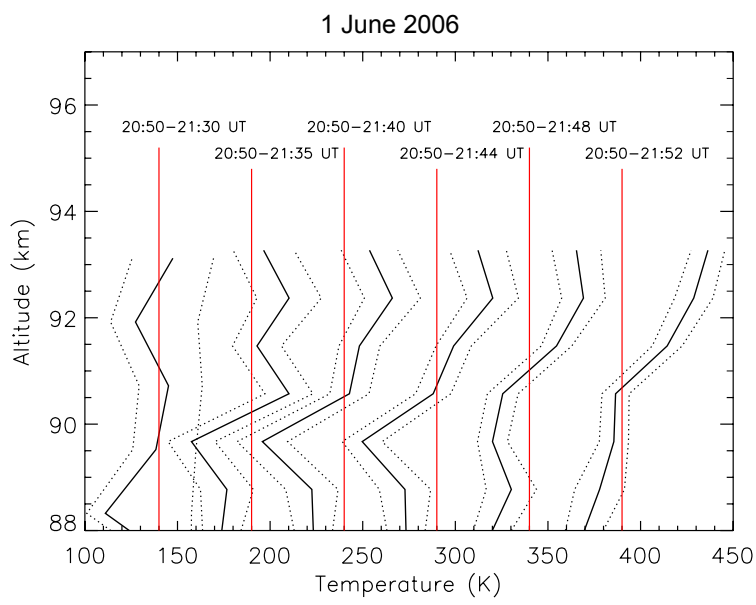

Fig. 11. Temperature profiles calculated with different time windows to show the temperature development in the altitude range above $90 \mathrm{~km}$. The plots are shifted by $50 \mathrm{~K}$ from profile to profile. The red line indicates $140 \mathrm{~K}$.

tion to the solar elevation angle and investigated the coincidence of sporadic E layers. All of the summer enhancements occurred in conjunction with sporadic E layers, six of them after the onset of the sporadic E layer. Other mechanisms like gravity-waves or tides have a strong impact on the summer Na layer, too. To understand the Na number density variations during summer better, we need to make more observations ideally simultaneously with the other instruments at ALOMAR and the Andøya Rocket Range.

Acknowledgements. Thanks to the staff of the ALOMAR observatory for their assistance, to M. Rietveld (EISCAT) for providing us with the ionograms from the EISCAT Troms $\varnothing$ Dynasonde and to NILU Troms $\emptyset$ for providing ECMWF data.

This research was supported by the Andøya Rocket Range, the NSF grant ATM-0545262, the AFOSR contract FA9550-06-C-0129, the Marie-Curie Intra-European Fellowship program of the European Community (MINERWA, No. 010333), and the Norwegian Research Council projects 165573 and 170855.

Topical Editor M. Pinnock thanks two anonymous referees for their help in evaluating this paper.

\section{References}

Arnold, K. S. and She, C.-Y.: Metal fluorescence lidar (light detection and ranging) and the middle atmosphere, Contemporary Physics, 44, 35-49, 2003.

Balsley, B. B., Ecklund, W. L., and Fritts, D. C.: VHF echoes from the high-altitude mesophere and lower thermosphere: observations and interpretations, J. Atmos. Sci., 40, 2451-2466, 1983.

Batista, P. P., Clemesha, B. R., and Simonich, D. M.: Horizontal structures in sporadic sodium layers at $23^{\circ} \mathrm{S}$, Geophys. Res. Lett, 18, 1027-1030, 1991.

Baumgarten G. and Thomas, G.: The importance of ice particle shape on UV measurements of polar mesospheric clouds: 
SBUV/2 observations, J. Atmos. Sol.-Terr. Phys., 68, 78-84, 2006.

Becker, E. and Schmitz, G.: Energy deposition and turbulent dissipation owing to gravity waves in the mesosphere, J. Atmos. Sci., 59, 54-68, 2002.

Bittner, M., Offermann, D., Graeff, H.-H., Donner, M., and Hamilton, K.: An 18-year time series of $\mathrm{OH}$ rotational temperatures and middle atmosphere decadal variations, J. Atmos. Terr. Phys., 64, 1147-1166, 2002.

Chapman, S.: Notes on Atmospheric Sodium, Astrophys. J., 90, 309-316, 1939.

Chen, H., She, C. Y., Searcy, P., and Korevaar, E.: Sodium-vapor dispersive Faraday filter, Opt. Lett., 18, 1019-1021, 1993.

Chen, H., White, M. A., Krueger, D. A., and She, C. Y.: Daytime mesopause temperature measurements with a sodium-vapor dispersive Faraday filter in a lidar receiver, Opt. Lett., 21, 10931095, 1996.

Chu, X., Pan, W., Papen, G. C., Gardner, C. S., and Gelbwachs, J. A.: Fe Boltzmann temperature lidar: Design, error analysis, and initial results at the North and South poles, Appl. Opt., 41, 4400-4410, 2002.

Clemesha, B. R., Kirchhoff, V. W. J. H., Simonich, D. M., and Takahashi, H.: Evidence of an extraterrestrial source for the mesospheric sodium layer, Geophys. Res. Lett., 5, 873-876, 1978.

Clemesha, B. R.: Sporadic neutral metal layers in the mesosphere and lower thermosphere, J. Atmos. Terr. Phys., 57, 725-736, 1995.

Collins, S. C., Plane, J. M. C., Kelly, M. C., Wright, T. G., Solán, P., Kane, T. J., Gerrard, A. J., Grime, B. W., Rollanson, R. J., Friedman, J. S., González, S. A., Zhou, Q., Sulzer, M. P., and Teply, C. A.: A study of the role of ion-molecule chemistry in the formation of sporadic sodium layers, J. Atmos. Sol. Terr. Phys., 64, 845-860, 2002.

Collins, R. L., Hallinan, T. J., Smith, R. W., and Hernandez, G.: Lidar observations of large high-altitude sporadic Na layer during active aurora, Geophys. Res. Lett., 23, 3655-3658, 1996.

Czechowski, P., Rüster, R., and Schmidt, G.: Variations of mesospheric structures in different seasons, Geophys. Res. Lett., 6, 459-462, 1979.

Dick, D. J. and Shay, T. M.: Ultrahigh-noise rejection optical filter, Opt. Lett., 16, 867-869, 1991.

Fiedler, J., Baumgarten, G., and von Cossart, G.: Mean diurnal variations of noctilucent clouds during 7 years of lidar observations at ALOMAR, Ann. Geophys., 23, 1175-1181, 2005, http://www.ann-geophys.net/23/1175/2005/.

Fricke, K. H. and von Zahn, U.: Mesopause temperatures derived from probing the hyperfine structure of the $\mathrm{D}_{2}$ resonance line of sodium by lidar, J. Atmos. Terr. Phys., 47(5), 499-512, 1985.

Friedman, J. S., González, Tepley, C. A., Zhou, Q., Sulzer, M. P., Collins, S. C., and Grime, B. W.: Simultaneous atomic and ion layer enhancements observed in the mesopause region over Arecibo during the Coqui II sounding rocket campaign, Geophys. Res. Lett., 27, 449-452, 2000.

Fritts, D. C., Williams, B. P., She, C. Y., Vance, D. J., Rapp, M., Lübken, F.-J., Müllemann, A., Schmidlin, F. J., and Goldberg, R. A.: Observations of extreme temperature and wind gradients near the summer mesopause during the MaCWAVE/MIDAS rocket campaign, Geophys. Res. Lett., 31, L24S06, doi:10.1029/2003GL019389, 2004.
Fritts, D. C., Vadas, S. L., and Yamada, Y.: An estimate of strong local body forcing and gravity wave radiation based on $\mathrm{OH}$ airglow and meteor radar observations, Geophys. Res. Lett., 29(10), 1429, doi:10.1029/2001GL013753, 2002.

Gardner, C. S., Senft, D. C., and Kwon, K. H.: Lidar observations of substantial sodium depletion in the summertime arctic mesophere, Nature, 332, 142-143, 1988.

Gardner, C. S.: Sporadic metal layers in the upper mesosphere, Faraday Discuss., 100, 431-439, 1995.

Garcia, R. R. and Solomon, S.: The effect of breaking gravity waves on the dynamics and chemical composition of the mesosphere and lower thermosphere, J. Geophys. Res., 90, 3850-3868, 1985.

Gavrilov, N. M., Fukao, S., and Nakamura, T.: Gravity wave intensity and momentum fluxes in the mesosphere over Shigaraki, Japan $\left(35^{\circ} \mathrm{N}, 136^{\circ} \mathrm{E}\right)$ during 1986-1997, Ann. Geophys., 18, 834-843, 2000,

http://www.ann-geophys.net/18/834/2000/.

Gerding, M., Alpers, M., von Zahn, U., Rollason, R. J., and Plane, J. M. C.: Atmospheric $\mathrm{Ca}$ and $\mathrm{Ca}^{+}$layers: Midlatitude observations and modeling, J. Geophys. Res., 105, 27 131-27 146, 2000.

Giebler, J. and Lübken, F.-J.: Density and temperature measurements in the lower thermosphere with the cone instrument, ESA SP-370, 101-106, 1995.

Goldberg, R. A., Fritts, D. C., Williams. B. P., Lübken, F.-J., Rapp, M., Singer, W., Lateck, R., Hoffmann, P., Müllemann, A., Baumgarten, G., Schmidlin, F. J., She, C.-Y., and Krueger, D. A.: The MaCWAVE/MIDAS rocket and ground-based measurements of polar summer dynamics: Overview and mean state structure, Geophys. Res. Lett, 31, L24S02, doi:10.1029/2004GL019411, 2004.

Hansen, G. and von Zahn, U.: Sudden sodium layers in polar latitudes, J. Atmos. Terr. Phys., 52, 585-608, 1990.

Hedin, A. E.: Neutral atmosphere empirical model from the surface to the lower Exosphere MSISE90, J. Geophys. Res., 96, 1159$1172,1991$.

Hedin, J.: Design and construction of a potassium Faraday filter for potassium lidar system daytime operation at Arecibo Observatory, Master thesis Luleå University of Technology, 2002:373 CIV, http://epubl.ltu.se/1402-1617/2002/373/ LTU-EX-02373-SE.pdf, 2002.

Heinrich, D., Blum, U., Williams, B., Vance, J., She, C.-Y., Singer, W., and Hoppe, U.-P.: Observations of wintertime mesopause temperatures with the ALOMAR Weber Na Lidar during winter 2004/05, ESA SP-590, 133-137, 2005.

Hoppe, U.-P.: Temperaturmessungen in 80 bis $100 \mathrm{~km}$ Höhe vom Boden aus durch Laser-angeregte Resonanz-Fluoreszenz am Na, Dissertation, Bonn University, ISSN-0172-8741, 1985.

Hoppe, U.-P., Hall, Ch., and Röttger, J.: First observations of summer polar mesospheric backscatter with a $224 \mathrm{MHz}$ radar, Geophys. Res. Lett., 15, 1, 28-31, 1988.

Jesse, O.: Auffallende Abenderscheinungen am Himmel, Meteorol. Zeitung, 2, 311, 312, 1885.

Kirwood, S.: Thin ion layers in the high-latitude lower ionosphere, Adv. Space Res., 19, 149-158, 1997.

Kurzawa, H. and von Zahn, U.: Sodium density and atmospheric. temperature in the mesopause region in polar summer, J. Atmos. Terr. Phys., 52, 981-993, 1990.

Kurzawa, H. and von Zahn, U.: Diurnal variation of the sodium layer at polar latitudes in summer, ESA SP-291, 253-256, 1989. 
Lie-Svendsen, Ø., Blix, T. A., and Hoppe, U.-P.: Modelling the plasma response to small-scale aerosol particle perturbations in the mesopause region, J. Geophys. Res., 108, 8442, doi:10.1029/2002JD002753, 2003.

Lindzen, R. S.: Turbulence and stress due to gravity wave and tidal breakdown, J. Geophys. Res., 86, 9707-9714, 1981.

Lübken, F.-J.: Thermal structure of the Arctic summer mesosphere, J. Geophys. Res., 104, 9135-9149, 1999.

Lübken, F.-J. and von Zahn: U., Thermal Structure of the Mesopause Region at Polar Latitudes, J. Geophys. Res., 96, 20 841-20 857, 1991.

Murgatroyd, R. J. and Singleton, F.: Possible meridional circulations in the stratosphere and mesosphere. Q. J. Roy. Meteor. Soc., 87, 125-135, 1961.

Nesse, H., Heinrich, D., Williams, B., Hoppe, U.-P., Stadsnes, J., Rietveld, M., Singer, W., Blum, U., Sandanger, M., and Trondsen, E.: A case study of a sudden sodium layer observed by the ALOMAR Weber Na lidar, Ann. Geophys., 26, 1071-1081, 2008.

Plane, J. M. C.: Atmospheric chemistry of meteoric metals, Chem. Rev., 103, 4963-4984, 2003.

Rapp, M. and Lübken, F.-J.: Polar mesosphere summer echoes (PMSE): Review of observations and current understanding, Atmos. Chem. Phys., 4, 2601-2633, 2004, http://www.atmos-chem-phys.net/4/2601/2004/.

Rapp, M., Gumbel, J., and Lübken, F.-J.: Absolute density measurements in the middle atmosphere, Ann. Geophys., 19, 571580, 2001, http://www.ann-geophys.net/19/571/2001/.

Schmidlin, F. J.: The inflatable sphere: A technique for the accurate measurement of middle atmosphere temperatures, J. Geophys. Res., 96, 22 673-22 682, 1991.

She, C. Y., Yu, J. R., Latifi, H., and Bills, R. E.: High-spectralresolution fluorescence light detection and ranging for mesospheric sodium temperature measurements, Appl. Opt., 31, 2095-2106, 1992.

She, C. Y.: Faraday filter for daytime observation of the mesopause region, ESA SP-397, 135-138, 1997.

She, C. Y., Vance, J. D., Williams, B. P., Krueger, D. A., Moosmüller, H., Gibson-Wilde, D., and Fritts, D. C.: Lidar studies of atmospheric dynamics near polar mesopause, EOS Trans. AGU, 83, 289-293, 2002.

Simonich, D. M., Clemesha, B. R., and Kirchhoff, V. W. J. H.: The mesospheric sodium layer at $23^{\circ} \mathrm{S}$ : nocturnal and seasonal variations, J. Geophys. Res., 84, 1543-1550, 1979.

Thomas, L. and Bhattacharyya, S. K.: Mesospheric temperatures deduced from laser observations of the $\mathrm{Na} \mathrm{D}_{2}$ line profile, 5th ESA Symp. Eur. Rocket Balloon Prog., 49-50, 1980.
Vance, J. D., She, C.-Y., and Moosmüller, H.: Continuouswave, all-solid-state, single-frequency $400-\mathrm{mW}$ source at $589 \mathrm{~nm}$ based on doubly resonant sum-frequency mixing in a monolithic lithium niobate resonator, Appl. Opt., 37, 4891-4896, 1998.

von Zahn, U. and Höffner, J.: Mesopause temperature profiling by potassium lidar, Geophys. Res. Lett., 23, 141-144, 1996.

von Zahn, U. and Hansen., G.: Sudden neutral sodium layers: a strong link to sporadic E layers, J. Atmos. Terr. Phys., 50, 93104, 1988.

von Zahn, U., von der Gathen, P., and Hansen, G.: Forced release of sodium from upper atmospheric dust particles., Geophys. Res. Lett., 14, 76-79, 1987.

von Zahn, U., Fricke, K. H., Gerndt, R., and Blix, T.: Mesospheric temperatures and the $\mathrm{OH}$ layer height as derived from groundbased lidar and $\mathrm{OH}^{*}$ spectrometry, J. Atmos. Terr. Phys., 49, 863-869, 1987.

Williams, B. P., Berkey, F. T., Sherman, J., and She, C.-Y.: Coincident extremely large sporadic sodium and sporadic E layers observed in the lower thermosphere over Colorado and Utah, Ann. Geophys., 25, 3-8, 2007, http://www.ann-geophys.net/25/3/2007/.

Williams, B. P., Vance, J. D., She, C.-Y., Fritts, D. C., Abe, T. and Thrane, E.: Sodium lidar measurements of waves and instabilities near the mesopause during the DELTA rocket campaign, Earth Planets Space, 58, 1131-1137, 2006a.

Williams, B. P., Fritts, D. C., She, C.-Y., and Goldberg, R. A.: Gravity wave propagation through a large semidiurnal tide and instabilities in the mesosphere and lower thermosphere during the winter 2003 MaCWAVE rocket campaign, Ann. Geophys., 24, 1199-1208, 2006b, http://www.ann-geophys.net/24/1199/2006/.

Williams, B. P., Croskey, C., She, C. Y., Mitchell, J. D., and Goldberg, R. A.: Sporadic sodium and sporadic-E layers observed during the summer 2002 MaCWAVE/MIDAS rocket campaign, Ann. Geophys., 1257-1266, 2006c.

Williams, B. P., Fritts, D. C., Wang, L., She, C. Y., Vance, J. D., Schmidlin, F. J., Goldberg, R. A., Müllemann, A., and Lübken, F.-J.: Gravity waves in the Arctic mesosphere during the MaCWAVE/MIDAS summer rocket program, Geophys. Res. Lett., 31, L24S05, doi:10.1029/204GL020049, 2004.

Zhou, Q., Mathews, J. D., and Tepley, C. A.: A proposed temperature dependent mechanism for the formation of sporadic sodium layers, J. Atmos. Terr. Phys., 55, 513-521, 1993. 